\title{
Thalidomide plus chemotherapy exhibit enhanced efficacy in the clinical treatment of T-cell non-Hodgkin's lymphoma: A prospective study of 46 cases
}

\author{
HONGYANG WU, CHENCHEN ZHAO, KANGSHENG GU, YANG JIAO, JIQING HAO and GUOPING SUN
}

Department of Medical Oncology, The First Affiliated Hospital of Anhui Medical University, Hefei, Anhui 230031, P.R. China

Received February 27, 2014; Accepted May 13, 2014

DOI: $10.3892 / \mathrm{mco} .2014 .307$

\begin{abstract}
The treatment of T-cell non-Hodgkin's lymphoma (T-NHL) remains challenging. There is currently no standard regimen for the treatment of T-NHL in the first- or second-line setting. Thalidomide was previously shown to exert antitumor effects through inhibiting angiogenesis, promoting apoptosis and immunomodulatory activity. However, all the previous studies on the treatment of lymphoma with thalidomide included patient samples of limited size. In the present study, 46 cases of eligible T-NHL patients were randomized into i) the control group (conventional combined chemotherapy, $\mathrm{n}=22$ ) and ii) the thalidomide group (thalidomide plus combined chemotherapy, $\mathrm{n}=24$ ). The median dose of thalidomide was $200 \mathrm{mg}$ (range, 150-400 mg) every night, without reported severe side effects. The clinical response to treatment was as follows: Complete response (CR) in 12 cases, partial response (PR) in 7, stable disease (SD) in 1 and progressive disease (PD) in 4 cases in the thalidomide group; and $\mathrm{CR}$ in 8 cases, $\mathrm{PR}$ in $6, \mathrm{SD}$ in 3 and $\mathrm{PD}$ in 5 cases in the control group. The CR rate was 50.0 and $36.4 \%$ in the thalidomide and the control groups, respectively $(\mathrm{P}<0.05)$. The median progression-free and overall survival were 12 and undefined months, respectively, in the thalidomide group and 6 and 17 months, respectively, in the control group. The toxicity profile was considered acceptable in both groups. Our results indicated that thalidomide plus combined chemotherapy may exhibit enhanced efficacy in the clinical treatment of T-NHL. In addition, this type of treatment may reduce the frequency of adverse gastrointestinal reactions and help alleviate fear of chemotherapy. Therefore, thalidomide plus combined chemotherapy may be a viable option for the clinical treatment of T-NHL.
\end{abstract}

Correspondence to: Dr Hongyang Wu, Department of Medical Oncology, The First Affiliated Hospital of Anhui Medical University, 210 Jixi Road, Hefei, Anhui 230022, P.R. China E-mail:wuhoya1970@163.com

Key words: non-Hodgkin's lymphoma, T-cell non-Hodgkin's lymphoma, thalidomide, chemotherapy, treatment

\section{Introduction}

T-cell non-Hodgkin's lymphomas (T-NHLs) are a group of malignant types of NHL. The incidence rate of T-NHL has been increasing worldwide over the last few years (1). In particular, the incidence rate of T-NHL in Asia was found to be higher compared to that in the United States and Europe (2-4). Chemotherapy or combined radiotherapy are currently the main treatment options for NHL. The overall survival (OS) of NHL has improved following the introduction of molecular-targeted drugs. However, when compared to B-cell lymphoma (B-NHL), most types of T-NHL remain difficult to diagnose, exhibit a more aggressive behaviour and are associated with worse outcomes (5). There is currently no standard regimen for the treatment of T-NHL in the first- or second-line setting $(6,7)$ and the recommended treatment identify and employ clinical trials as described in National Comprehensive Cancer Network guideline.

Thalidomide, a synthetic glutamic acid derivative, was widely used as a sedative and antiemetic in Europe and Canada in the 1950s (8). However, it was withdrawn from the market due to its teratogenic side effects that caused limb deformities in tens of thousands of infants (9). It was recently demonstrated that thalidomide exerts antitumor effects through inhibiting angiogenesis (10), promoting apoptosis (11) and immunomodulatory activity. Thalidomide has been used in the treatment of multiple myeloma (12,13), Kaposi's sarcoma (14), mantle cell lymphoma (15), idiopathic myelofibrosis (16) and other diseases (17). However, all the previous studies on the treatment of lymphoma with thalidomide included patient samples of limited size. We conducted a randomized trial on 46 cases of T-NHL patients to determine whether thalidomide combined with chemotherapy may exhibit enhanced efficacy in the clinical treatment of T-NHL.

\section{Materials and methods}

Patients. Eligible T-NHL patients were selected from the Department of Medical Oncology of the First Affiliated Hospital of Anhui Medical University (Hefei, Anhui, China) between January, 2009 and June, 2013. The inclusion criteria were as follows: i) The patient diagnosis was confirmed by histological and immunohistochemical examination according to the $2008 \mathrm{WHO}$ classification of haematopoietic 
and lymphoid tissue neoplasms (18); ii) the patients were aged 18-75 years and had a total leukocyte count of $>4.0 \times 10^{9} / 1$, a platelet count of $>100 \times 10^{9} / 1$, serum bilirubin, alanine aminotransferase and alkaline phosphatase levels less than two times the upper limit of normal, a 24-h creatinine clearance of $>60 \mathrm{ml} / \mathrm{min}$ and no significant abnormalities on ECG; iii) the ECOG performance status score was $\leq 2$ (19) and the expected survival time was $>3$ months; and iv) all the patients received at least two cycles of chemotherapy and were allowed to receive local radiotherapy (except to the target lesion). The clinical data and follow-up information, including age, gender, B symptoms, number of extranodal organ involvement, bone marrow aspiration or biopsy results, lactate dehydrogenase (LDH) level, T lymphocyte subsets and Ann Arbor clinical stage were obtained from the hospital records or by telephone. Following treatment, the clinical results were evaluated over time. Patients with lymphoma of the central nervous system, bone marrow infiltration of $>25 \%$ as determined by histological examination, HIV infection or any major organ dysfunction were excluded from this study.

The study protocol was approved by the local Institutional Ethics Committee and informed consent was obtained from all the participants.

Chemotherapy. The patients were randomized into i) the control group (conventional combined chemotherapy) and ii) the thalidomide group (thalidomide plus combined chemotherapy). In the control group, the selection of the chemotherapeutic regimen was mainly based on pathological and clinical stage; the standard CHOP regimen (20) was mainly used, with administration of one cycle every 3 weeks consisting of cyclophosphamide, adriamycin, vincristine and prednisone. Antiemetic treatment was administered prior to chemotherapy. Certain patients were administered sodium bicarbonate to alkalinize the urine. In the thalidomide group, thalidomide was synchronously administered orally every night during and after chemotherapy. The initial dose was $100 \mathrm{mg} /$ day, increasing by $50 \mathrm{mg} /$ day every week (21). The selection of the chemotherapeutic regimen and the management of chemotherapy-related side effects were similar to the control group.

Clinical assessment. The size of the tumors was measured by computed tomography (CT), positron emission tomography/ $\mathrm{CT}$ and/or magnetic resonance imaging at baseline, after every 2 cycles and every 9 weeks during follow-up. The response to treatment was evaluated according to the Response Evaluation Criteria in Solid Tumors, version 1.1 (22) as follows: Complete response (CR): disappearance of all target lesions; any pathological lymph nodes (target or non-target) were required to exhibit a reduction in the short axis to $<10 \mathrm{~mm}$; partial response (PR): at least $30 \%$ decrease in the sum of the diameters of the target lesions, with the baseline sum diameters used as reference and no appearance of new lesions; progressive disease (PD): at least $20 \%$ increase in the sum of the diameters of the target lesions, with the smallest sum on study (this includes the baseline sum if that is the smallest on study) used as reference. In addition to the relative increase of $20 \%$, the sum was also required to demonstrate an absolute increase of $\geq 5 \mathrm{~mm}$; and stable disease (SD): neither sufficient shrinkage to qualify for PR, nor sufficient increase to qualify for PD, with the smallest sum diameters while on study used as reference.

The overall response was determined as $\mathrm{CR}+\mathrm{PR}+\mathrm{SD}$ and the objective response as $\mathrm{CR}+\mathrm{PR}$. Hematological and other toxicities were evaluated for every treatment cycle according to version 3.0 of the Common Toxicity Criteria of the National Cancer Institute of Canada (23). If any toxicity $>$ grade 1 was observed in a former cycle, the dose of chemotherapy was decreased in the subsequent cycle.

Follow-up. Clinical data and follow-up information were mainly obtained from hospital records or by telephone. Other methods were also used, including medical follow-up letters. OS was defined as the time from treatment initiation until the date of death or last follow-up. Progression-free survival (PFS) was defined as the time from treatment initiation to disease progression or to termination of the follow-up if no relapse occured or death from any cause. Patients that were lost to the follow-up were excluded. Our follow-up ended September 30, 2013 and three cases were lost $(6.5 \%)$.

Statistical analysis. The SPSS 18.0 statistical software package was used for statistical processing. The survival rate was calculated and a survival curve was drawn using the GraphPad Prism method. The measurement data of the control and thalidomide treatment groups were compared using the t-test and the count data were compared using the Fisher's exact probability test. $\mathrm{P}<0.05$ was considered to indicate a statistically significant difference.

\section{Results}

Clinical characteristics. A total of 46 patients were enrolled in this study, with 24 patients assigned to the thalidomide group and 22 to the control group (Table I). The patients included 32 men and 14 women, with 36 patients undergoing primary treatment and 10 undergoing treatment for recurrence. The median age of the patients was 47.5 years (range, 18-77 years). The T-NHL subtypes were as follows: 21 cases of natural killer/T-cell lymphoma, 9 cases of peripheral T-cell lymphoma, 7 cases of anaplastic lymphoma kinase-positive anaplastic large-cell lymphoma, 4 cases of angioimmunoblastic T-cell lymphoma (AITL), 2 cases of precursor T-lymphoblastic lymphoma, 1 case of subcutaneous panniculitis-like T-cell lymphoma, 1 case of primary cutaneous anaplastic large-cell lymphoma and 1 case of adult T-cell leukemia/lymphoma. Prior to treatment, 15 patients were diagnosed with stage I, 8 with stage II, 10 with stage III and 13 with stage IV disease.

Clinical response. Each patient completed at least two cycles of treatment. In the 24 cases included in the thalidomide group, the median dose of thalidomide was $200 \mathrm{mg}$ (range, 150-400 mg) every night, without reported severe side effects. The response was CR in 12 cases, $\mathrm{PR}$ in 7, SD in 1 and $\mathrm{PD}$ in 4 cases. In the 22 cases of the control group, the response was $\mathrm{CR}$ in 8 cases, $\mathrm{PR}$ in $6, \mathrm{SD}$ in 3 and $\mathrm{PD}$ in 5 cases. The $\mathrm{CR}$ rate was 50 and $36.4 \%$ in the thalidomide and the control groups, respectively $(\mathrm{P}<0.05)$. The overall response rate $(\mathrm{CR}+\mathrm{PR})$ 
Table I. Clinical characteristic of the 46 T-NHL patients.

\begin{tabular}{|c|c|c|c|c|c|c|c|c|c|c|c|}
\hline No. & Gender & $\begin{array}{l}\text { Age } \\
\text { (yrs) }\end{array}$ & Type & Stage & $\begin{array}{l}\text { Primary or } \\
\text { recurrence }\end{array}$ & Group & Combined with & Cycles & $\mathrm{CA}^{\mathrm{a}}$ & $\begin{array}{l}\text { PFS } \\
(\mathrm{mo})\end{array}$ & $\begin{array}{c}\mathrm{OS} \\
(\mathrm{mo})\end{array}$ \\
\hline 1 & M & 45 & $\mathrm{NK} / \mathrm{T}$ & I & Primary & TLD & $\mathrm{CHOP}^{\mathrm{b}}+\mathrm{RT}^{\mathrm{c}}$ & 6 & $\mathrm{CR}$ & $>42$ & $>42$ \\
\hline 2 & M & 42 & $\mathrm{NK} / \mathrm{T}$ & I & Primary & TLD & $\mathrm{CHOP}^{\mathrm{b}}+\mathrm{RT}^{\mathrm{c}}$ & 6 & $\mathrm{CR}$ & $>33$ & $>33$ \\
\hline 3 & $\mathrm{~F}$ & 40 & ALCL & I & Primary & TLD & $\mathrm{CHOP}^{\mathrm{b}}$ & 6 & $\mathrm{CR}$ & $>32$ & $>32$ \\
\hline 4 & $\mathrm{~F}$ & 51 & $\mathrm{NK} / \mathrm{T}$ & II & Recurrence & TLD & $\mathrm{DICE}^{\mathrm{d}}$ & 4 & PD & 3 & 5 \\
\hline 5 & M & 77 & AITL & II & Primary & TLD & $\mathrm{COP}^{\mathrm{e}}$ & 4 & PR & 3 & 7 \\
\hline 6 & M & 33 & PTCL & III & Recurrence & TLD & $\mathrm{CHOP}^{\mathrm{b}}+\mathrm{RT}^{\mathrm{c}}$ & 4 & PR & 2 & $>5$ \\
\hline 7 & M & 70 & AITL & III & Primary & TLD & $\mathrm{CHOP}^{\mathrm{b}}$ & 4 & PR & 5 & $>12$ \\
\hline 8 & M & 41 & $\mathrm{NK} / \mathrm{T}$ & $\mathrm{I}$ & Primary & TLD & $\mathrm{CHOP}^{\mathrm{b}}+\mathrm{Gem}^{-\mathrm{RT}^{\mathrm{c}}}$ & 6 & $\mathrm{CR}$ & $>26$ & $>26$ \\
\hline 9 & M & 45 & PTCL & II & Recurrence & TLD & $\mathrm{CHOP}^{\mathrm{b}}$ & 3 & $\mathrm{CR}$ & $>15$ & $>15$ \\
\hline 10 & M & 53 & T-LBL & IV & Recurrence & TLD & FMD $^{\mathrm{f}}$ & 2 & PR & 7.5 & 11.5 \\
\hline 11 & M & 75 & AITL & IV & Primary & TLD & $\mathrm{CHOP}^{\mathrm{b}}$ & 2 & SD & 4 & 7 \\
\hline 12 & M & 39 & PTCL & IV & Primary & TLD & $\mathrm{CHOP}^{\mathrm{b}}+\mathrm{DDP}+\mathrm{RT}^{\mathrm{c}}$ & 7 & PR & 9 & 21 \\
\hline 13 & $\mathrm{~F}$ & 32 & SPTCL & $\mathrm{I}$ & Primary & TLD & $\mathrm{CHOP}^{\mathrm{b}}+\mathrm{DDP}+\mathrm{RT}^{\mathrm{c}}$ & 6 & CR & $>21$ & $>21$ \\
\hline 14 & M & 71 & $\mathrm{NK} / \mathrm{T}$ & IV & Recurrence & TLD & $\mathrm{CHOP}^{\mathrm{b}}+\mathrm{GEM}$ & 5 & CR & 19 & $>21$ \\
\hline 15 & $\mathrm{~F}$ & 50 & AITL & IV & Primary & TLD & $\mathrm{CHOP}^{\mathrm{b}}+\mathrm{GEM}$ & 5 & $\mathrm{CR}$ & $>18$ & $>18$ \\
\hline 16 & M & 48 & $\mathrm{NK} / \mathrm{T}$ & IV & Recurrence & TLD & GEM+L-OHP & 7 & CR & $>16$ & $>16$ \\
\hline 17 & $\mathrm{~F}$ & 73 & C-ALCL & IIIE & Recurrence & TLD & $\mathrm{CHOP}^{\mathrm{b}}$ & 2 & $\mathrm{PD}$ & 1 & $>8$ \\
\hline 18 & $\mathrm{~F}$ & 54 & ALCL & III & Recurrence & TLD & $\mathrm{DICE}^{\mathrm{d}}$ & 4 & PR & 12 & $>14$ \\
\hline 19 & $\mathrm{~F}$ & 58 & $\mathrm{NK} / \mathrm{T}$ & III & Primary & TLD & $\mathrm{CHOP}^{\mathrm{b}}+\mathrm{RT}^{\mathrm{c}}$ & 2 & $\mathrm{CR}$ & $>13$ & $>13$ \\
\hline 20 & $\mathrm{~F}$ & 74 & $\mathrm{NK} / \mathrm{T}$ & IV & Primary & TLD & GEM+L-OHP & 2 & PD & 2 & 3 \\
\hline 21 & $\mathrm{~F}$ & 60 & $\mathrm{NK} / \mathrm{T}$ & $\mathrm{I}$ & Primary & TLD & $\mathrm{GEM}+\mathrm{L}-\mathrm{OHP}+\mathrm{RT}^{\mathrm{c}}$ & 4 & $\mathrm{CR}$ & $>12$ & $>12$ \\
\hline 22 & M & 45 & $\mathrm{NK} / \mathrm{T}$ & I & Primary & TLD & GEM+L-OHP & 2 & PD & 1 & 3 \\
\hline 23 & M & 56 & $\mathrm{NK} / \mathrm{T}$ & II & Primary & TLD & $\mathrm{CHOP}^{\mathrm{b}}+\mathrm{RT}^{\mathrm{c}}$ & 2 & PR & 3 & 3 \\
\hline 24 & $\mathrm{~F}$ & 60 & $\mathrm{NK} / \mathrm{T}$ & I & Primary & TLD & GEM+L-OHP+RT ${ }^{\mathrm{c}}$ & 3 & $\mathrm{CR}$ & $>8$ & $>8$ \\
\hline 25 & M & 23 & PTCL & IV & Primary & Control & $\mathrm{CHOP}^{\mathrm{b}}$ & 2 & $\mathrm{PD}$ & 2 & 4 \\
\hline 26 & M & 47 & $\mathrm{NK} / \mathrm{T}$ & $\mathrm{I}$ & Primary & Control & $\mathrm{CHOP}^{\mathrm{b}}+\mathrm{RT}^{\mathrm{c}}$ & 6 & CR & $>37$ & $>37$ \\
\hline 27 & M & 60 & PTCL & III & Primary & Control & $\mathrm{CHOP}^{\mathrm{b}}$ & 6 & CR & $>36$ & $>36$ \\
\hline 28 & $\mathrm{~F}$ & 40 & PTCL & IV & Primary & Control & $\mathrm{CHOP}^{\mathrm{b}}+\mathrm{GEM}$ & 5 & PR & 6 & 10 \\
\hline 29 & M & 72 & ALCL & IV & Primary & Control & $\mathrm{CHOP}^{\mathrm{b}}+\mathrm{RT}^{\mathrm{c}}$ & 6 & $\mathrm{SD}$ & 6 & 0 \\
\hline 30 & $\mathrm{M}$ & 58 & PTCL & III & Primary & Control & $\mathrm{CHOP}^{\mathrm{b}}$ & 2 & PR & $>3$ & $>3$ \\
\hline 31 & $\mathrm{~F}$ & 35 & $\mathrm{NK} / \mathrm{T}$ & II & Primary & Control & $\mathrm{CHOP}^{\mathrm{b}}$ & 2 & $\mathrm{PD}$ & 0 & 3 \\
\hline 32 & $\mathrm{M}$ & 37 & $\mathrm{NK} / \mathrm{T}$ & $\mathrm{I}$ & Primary & Control & $\mathrm{CHOP}^{\mathrm{b}}+\mathrm{RT}^{\mathrm{c}}$ & 4 & $\mathrm{CR}$ & $>34$ & $>34$ \\
\hline 33 & M & 29 & ALCL & III & Recurrence & Control & $\mathrm{CHOP}^{\mathrm{b}}+\mathrm{RT}^{\mathrm{c}}$ & 6 & $\mathrm{SD}$ & 6 & $>11$ \\
\hline 34 & M & 65 & ATCL & IV & Recurrence & Control & GEM+L-OHP & 3 & $\mathrm{SD}$ & 5 & 7 \\
\hline 35 & M & 65 & $\mathrm{NK} / \mathrm{T}$ & II & Primary & Control & $\mathrm{CHOP}^{\mathrm{b}}$ & 2 & PR & 5 & 6 \\
\hline 36 & M & 58 & $\mathrm{NK} / \mathrm{T}$ & $\mathrm{I}$ & Primary & Control & $\mathrm{CHOP}^{\mathrm{b}}+\mathrm{RT}^{\mathrm{c}}$ & 2 & PR & 2 & 8 \\
\hline 37 & M & 38 & $\mathrm{NK} / \mathrm{T}$ & I & Primary & Control & $\mathrm{GP}^{\mathrm{h}}+\mathrm{DXM}$ & 2 & PD & 2 & 4 \\
\hline 38 & $\mathrm{~F}$ & 62 & PTCL & I & Primary & Control & $\mathrm{CHOP}^{\mathrm{b}}+\mathrm{RT}^{\mathrm{c}}$ & 6 & $\mathrm{CR}$ & $>26$ & $>26$ \\
\hline 39 & M & 61 & $\mathrm{NK} / \mathrm{T}$ & $\mathrm{I}$ & Primary & Control & $\mathrm{CHOP}^{\mathrm{b}}+\mathrm{RT}^{\mathrm{c}}$ & 6 & $\mathrm{CR}$ & $>23$ & $>23$ \\
\hline 40 & M & 40 & $\mathrm{NK} / \mathrm{T}$ & II & Primary & Control & $\mathrm{CHOP}^{\mathrm{b}}$ & 6 & $\mathrm{CR}$ & $>21$ & $>21$ \\
\hline 41 & M & 69 & PTCL & IV & Primary & Control & $\mathrm{CHOP}^{\mathrm{b}}$ & 8 & $\mathrm{CR}$ & 11 & 17 \\
\hline 42 & M & 65 & ALCL & III & primary & Control & $\mathrm{CHOP}^{\mathrm{b}}$ & 2 & PD & 1 & 3 \\
\hline 43 & M & 18 & ALCL & IV & Primary & Control & $\mathrm{CHOP}^{\mathrm{b}}$ & 2 & PR & 1 & $>6$ \\
\hline 44 & M & 65 & ALCL & III & Primary & Control & $\mathrm{CHOP}^{\mathrm{b}}$ & 2 & PD & 1 & 3 \\
\hline 45 & $\mathrm{~F}$ & 68 & T-LBL & I & Primary & Control & $\mathrm{CHOP}^{\mathrm{b}}$ & 4 & PR & 15 & $>15$ \\
\hline 46 & $\mathrm{M}$ & 36 & $\mathrm{NK} / \mathrm{T}$ & II & Primary & Control & $\mathrm{EP}^{\mathrm{g}}$ & 5 & $\mathrm{CR}$ & $>7$ & $>7$ \\
\hline
\end{tabular}

${ }^{\mathrm{a}}$ Clinical assessment. ${ }^{\mathrm{b}} \mathrm{Cyclophosphamide,} \mathrm{adriamycin}$, vincristine and prednisone. ${ }^{\mathrm{C}}$ Local radiotherapy. ${ }^{\mathrm{d}}$ Dexamethasone, ifosfamide, cisplatin and etoposide. ${ }^{\mathrm{e}} \mathrm{Cyclophosphamide,} \mathrm{vincristine} \mathrm{and} \mathrm{prednisone.}{ }^{\mathrm{f}}$ Fludarabine, mitoxantrone and dexamethasone. ${ }^{\mathrm{g}}$ Etoposide and cisplatin. ${ }^{\mathrm{h}} \mathrm{Gemcitabine}$ and cisplatin. T-NHL, T-cell non-Hodgkin's lymphoma; PFS, progression-free survival; OS, overall survival; M, male; F, female; NK/T, natural killer/T-cell lymphoma; ALCL, anaplastic lymphoma kinase-positive anaplastic large-cell lymphoma; AITL, angioimmunoblastic T-cell lymphoma; PTCL, peripheral T-cell lymphoma; T-LBL, precursor T-lymphoblastic lymphoma; SPTCL, subcutaneous panniculitis-like T-cell lymphoma; C-ALCL, primary cutaneous anaplastic large-cell lymphoma; ATCL, adult T-cell leukemia/lymphoma; TLD, thalidomide; GEM, gemcitabine; L-OHP, oxaliplatin; DXM, dextromethorphan; CR, complete response; PD, progressive disease; PR, partial response; SD, stable disease. 


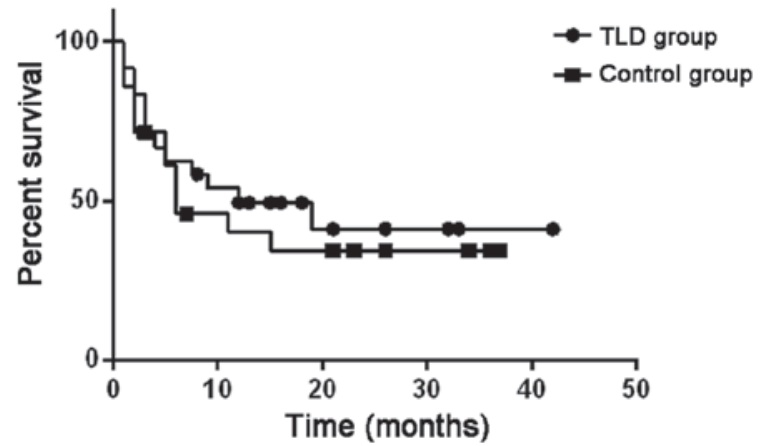

Figure 1. Progression-free survival (PFS) curve of 46 patients with T-cell non-Hodgkin's lymphoma. The median PFS was longer in the thalidomide (TLD) group (12 months) compared to that in the control group (6 months).

was 79.2 and $63.6 \%$ in the thalidomide and the control groups, respectively $\left(\chi^{2}=1.90, \mathrm{P}>0.05\right)$.

The PFS curves are shown in Fig. 1. The median PFS was 12 months in the thalidomide group and 6 months in the control group. Therefore, the PFS was longer by 6 months in the thalidomide group compared to that in the control group.

The OS curves are shown in Fig. 2. The median OS in the thalidomide group was undefined and in the control group it was 17 months. Therefore, the OS was longer in the thalidomide group compared to that in the control group.

LDH level and changes in the T lymphocytic subsets prior to and after chemotherapy. Prior to chemotherapy, the LDH level was $753.32 \pm 482.58$ and $811.25 \pm 424.67 \mathrm{U} / 1$ in the control and the thalidomide groups, respectively, without a significant difference between the two groups. After chemotherapy, the LDH level was $415.54 \pm 150.36 \mathrm{U} / 1$ in the control group and $180.62 \pm 131.17 \mathrm{U} / \mathrm{l}$ in the thalidomide group in the proportion of CR + PR patients. The difference between the two groups was statistically significant $(\mathrm{P}<0.05)$ (data not shown). When we compared the changes in $\mathrm{T}$ lymphocyte subsets prior to and after chemotherapy, we observed no statistically significant difference between the two groups $(\mathrm{P}>0.05)$ (data not shown).

Evaluation of side effects and safety in the two treatment groups. The majority of the patients $(\mathrm{n}=36)$ developed chemotherapy-related side effects. A total of 15 patients developed grade 2 gastrointestinal reactions, 6 exhibited weakness, 5 had an infection (severe in 1 patient), 5 developed limb peripheral neuritis, 3 exhibited mild liver function abnormalities and 1 patient had drowsiness. A total of 3 patients previously had sleep abnormalities, but improved after taking thalidomide for 2 weeks. In addition, 2 patients developed grade 1 oral mucositis and there was 1 case of cerebral thrombosis. There was no reported renal or cardiac toxicity, no drug-induced fever or rash and no treatment-related deaths in the two groups.

\section{Discussion}

In this study, of the 46 patients with T-NHL lymphoma, 24 were randomly selected and received treatment with thalidomide combined with chemotherapy. We observed that the CR rate and overall response rate (CR + PR) were higher in the thalidomide group (50 and $79.2 \%$, respectively) compared to those in

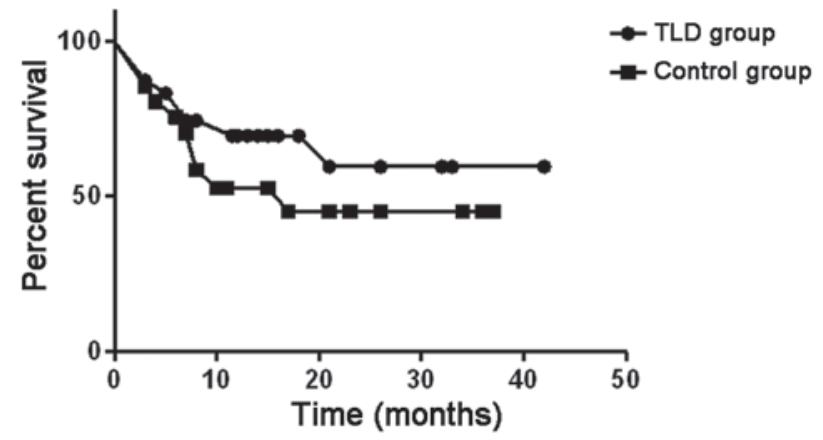

Figure 2. Overall survival (OS) curve of 46 patients with T-cell non-Hodgkin's lymphoma. The median OS was longer in the thalidomide (TLD) group (undefined months) compared to that in the control group (17 months).

the control group (36.4 and 63.6\%, respectively). The median PFS and OS were also longer in thalidomide group. Our results demonstrated that thalidomide combined with chemotherapy enhances the clinical efficacy of T-NHL treatment.

Over the last few years, an increasing number of studies reported that vascular endothelial growth factor was associated with the incidence, development and angiogenesis of malignant tumors (24) and anti-angiogenic therapy has become one of the most important methods in antitumor therapy. Thalidomide was gradually introduced in the treatment of malignant tumors due to its anti-angiogenic properties (10). Clinical and experimental data demonstrated that thalidomide effectively inhibited tumor growth, invasion and metastasis in multiple myeloma, colon cancer (25) and NHL (17). Therefore, thalidomide plus dexamethasone was approved by the Food and Drug Administration as a first-line regimen for multiple myeloma in May, 2006 (13).

The mechanism of action of thalidomide is complex and may involve the suppression of tumor necrosis factor- $\alpha$ (TNF- $\alpha$ ) and interferon- $\gamma$ secretion (26), which are known to upregulate endothelial cell integrin expression, a process crucial for new vessel formation (27). Thalidomide inhibits the secretion of basic fibroblast growth factor, an angiogenic factor secreted by human tumors (28), thus reducing tumor-associated macrophage infiltration, possibly through suppressing the expression of endothelial cell adhesion molecules (29). Thalidomide also suppresses TNF- $\alpha$-induced intercellular adhesion molecule-1 expression through inhibiting nuclear factor- $\kappa \mathrm{B}(30)$. A recent study (31) identified cereblon (CRBN) as the primary teratogenic target of thalidomide. CRBN is also required for the antimyeloma activity of thalidomide and other related drugs, referred to as immune-modulatory drugs (IMiDs). Low CRBN expression was found to be correlated with drug resistance in myeloma cell lines and primary myeloma cells. CRBN was also implicated in several effects of IMiDs, such as downregulation of TNF- $\alpha$ and T-cell activity.

Strupp et al (32) were the first to report the application of thalidomide in the treatment of lymphoma. Two AILT patients were treated with thalidomide as anti-angiogenic therapy and achieved complete remission. Subsequently, Wilson et al (33) reported one case of mantle cell lymphoma treated with thalidomide. That patient had experienced several tumor relapses and treatment by chemotherapy, steroids and rituximab had failed. The patient received daily single-agent thalidomide by oral 
ingestion at a dose of $800 \mathrm{mg}$ and achieved a partial remission, which was maintained for 6 months. Additional studies also reported cases of refractory mantle cell lymphoma or recurrent lymphoma successfully treated with thalidomide $(15,34,35)$, achieving an overall response rate of $81 \%$, with a CR rate of $31 \%$, when thalidomide was used in combination with rituximab in 16 relapsed mantle cell lymphoma patients.

In China, $\mathrm{Su}$ et al (36) reported that the overall response rate using the $\mathrm{CHOP}$ regimen with etoposide, with vs. without thalidomide, was 73.91 vs. 39.13\%, respectively, in advanced NHL. The 1- and 2-year survival rates were 86.96 and $56.52 \%$, respectively. There was no difference in the 1-year survival rate between the two groups; however, there was a significant difference in the 2-year survival rate. The major adverse reactions associated with the combination of chemotherapy and thalidomide were leucopenia, drowsiness, constipation, bloating and fatigue. Grade 3-4 leucopenia occurred in $\sim 15.0 \%$ of the patients who developed chemotherapy-related reactions. The results suggested that thalidomide may be used in the treatment of lymphoma.

The majority of the T-cell lymphoma types are aggressive. Therefore, they are not easily cured, even with autologous stem cell transplantation. Damaj et al (37) reported three cases of relapsed refractory T-cell lymphoma that exhibited a good tumor response under treatment with thalidomide: One patient achieved a transient PR and the remaining two patients achieved a complete resolution of the symptoms and the tumor masses. One of these two patients remained alive on low-dose thalidomide maintenance therapy, whereas the other succumbed to an aggressive relapse, while off thalidomide, 1 month after intensive chemotherapy-radiotherapy. Dogan et al (38) reported a case of a 78-year-old female patient with AITL confirmed by lymph node biopsy. After declining the standard treatment options, the patient agreed to treatment with $200 \mathrm{mg}$ daily thalidomide, which was maintained for 15 months and was well tolerated, except for a mild sensory neuropathy.

A certain dosage range of thalidomide is considered to be safe, as well as effective. It was previously reported (39) that thalidomide increased the patients' appetite and body weight, improved sleep and relieved the stress associated with advanced cancer. Oral thalidomide is easy to administer, cost-effective and has tolerable side effects; therefore, its application in clinical practice is feasible and convenient. It has been, however, associated with an increased risk of venous thromboembolism (40). In our study, the median dose of oral thalidomide was $200 \mathrm{mg}$ daily. Other side effects reported in the literature, such as rash, bradycardia, hypothyroidism and peripheral neuropathy, were not recorded in our study. We hypothesized that thalidomide may be used over a longer period of time, due to its slower anti-angiogenic effect.

In the present study, we demonstrated that thalidomide effectively reduced LDH in the blood prior to and after chemotherapy, suggesting that it may improve the prognosis of T-NHL patients. However, the T cell subsets did not change significantly prior to and after chemotherapy, possibly due to the limited effect of thalidomide on the immune system. Newly developed drugs that are similar to thalidomide, such as lenalidomide (Revlimid, CC-5013) and actimid (CC-4047) have been confirmed to exert significant regulatory effects on the human immune system (41).
These results suggested that drugs similar to thalidomide may have a place in cancer treatment.

In conclusion, we randomly selected 24 patients among 46 cases of T-NHL lymphoma and administered treatment with thalidomide combined with chemotherapy, achieving a significant improvement in the $\mathrm{CR}$ rate and overall response rate $(\mathrm{CR}+\mathrm{PR})$. In addition, the PFS and OS were prolonged, with no associated increase in toxicity. Although the differences were not considered statistically significant, it may be of value to investigate further by expanding the sample size or grouping by thalidomide dose and certain subtypes of T-NHL. Thalidomide combined with chemotherapy may reduce the incidence of gastrointestinal reactions and the psychological fear of chemotherapy in cancer patients and may represent a viable treatment option for T-NHL.

\section{Acknowledgements}

This study was supported by the Health Bureau of Anhui Province (grant no. 09B114).

\section{References}

1. Siegel R, Naishadham D and Jemal A: Cancer statistics, 2013. CA Cancer J Clin 63: 11-30, 2013.

2. Ekström-Smedby K: Epidemiology and etiology of non-Hodgkin lymphoma - a review. Acta Oncol 45: 258-271, 2006.

3. Vose J, Armitage J and Weisenburger D; International T-Cell Lymphoma Project: International peripheral T-cell and natural killer/T-cell lymphoma study: pathology findings and clinical outcomes. J Clin Oncol 26: 4124-4130, 2008.

4. Shiels MS, Engels EA, Linet MS, et al: The epidemic of non-Hodgkin lymphoma in the United States: disentangling the effect of HIV, 1992-2009. Cancer Epidemiol Biomarkers Prev 22: 1069-1078, 2013.

5. Gisselbrecht C, Gaulard P,Lepage E, et al: Prognostic significance of T-cell phenotype in aggressive non-Hodgkin's lymphomas. Groupe d'Etudes des Lymphomes de l'Adulte (GELA). Blood 92: 76-82, 1998.

6. Reimer P, Rüdiger T, Geissinger E, et al: Autologous stem cell transplantation as first-line therapy in peripheral T-cell lymphomas: results of a prospective multicenter study. J Clin Oncol 27: 106-113, 2009.

7. Jagadeesh D and Smith MR: Novel targeted therapies in peripheral T cell lymphoma. Discov Med 15: 367-378, 2013.

8. Somers GF: Pharmacological properties of thalidomide (alpha-phthalimido glutarimide), a new sedative hypnotic drug. Br J Pharmacol Chemother 15: 111-116, 1960.

9. Tseng S, Pak G, Washenik K, Pomeranz MK and Shupack JL: Rediscovering thalidomide: a review of its mechanism of action, side effects, and potential uses. J Am Acad Dermatol 35: 969-979, 1996.

10. Kruse FE, Joussen AM, Rohrschneider K, Becker MD and Völcker HE: Thalidomide inhibits corneal angiogenesis induced by vascular endothelial growth factor. Graefes Arch Clin Exp Ophthalmol 236: 461-466, 1998.

11. Aseffa A, Dietrich MA and Shannon EJ: Effect of thalidomide on apoptosis of lymphocytes and neutrophils. Immunopharmacol Immunotoxicol 19: 313-326, 1997.

12. Singhal S, Mehta J, Desikan R, et al: Antitumor activity of thalidomide in refractory multiple myeloma. N Engl J Med 341: 1565-1571, 1999.

13. FDA: FDA Approves Thalomid (thalidomide) to Treat Multiple Myeloma. http://www.fda.gov/Drugs/DrugSafety/PostmarketDrugSafetyInformationforPatientsandProviders/ucm107296. htm. Accessed May 18, 2014.

14. Krown SE: Management of Kaposi sarcoma: the role of interferon and thalidomide. Curr Opin Oncol 13: 374-381, 2001.

15. Kaufmann H, Raderer M, Wöhrer S, et al: Antitumor activity of rituximab plus thalidomide in patients with relapsed/refractory mantle cell lymphoma. Blood 104: 2269-2271, 2004. 
16. Strupp C, Germing U, Scherer A, et al: Thalidomide for the treatment of idiopathic myelofibrosis. Eur J Haematol 72: 52-57, 2004.

17. Ramírez J, Wu K, Janisch L, et al: The effect of thalidomide on the pharmacokinetics of irinotecan and metabolites in advanced solid tumor patients. Cancer Chemother Pharmacol 68: 1629-1632, 2011

18. Swerdlow SH, Campo E, Harris NL, et al (eds): WHO Classification of Tumours of Haematopoietic and Lymphoid Tissues. 4th edition. International Agency for Research on Cancer Press, Lyon, 2008.

19. Oken MM, Creech RH, Tormey DC, et al: Toxicity and response criteria of the Eastern Cooperative Oncology Group. Am J Clin Oncol 5: 649-655, 1982.

20. Huang HQ, Peng YL, Lin XB, et al: Clinical outcomes of 106 patients with peripheral T-cell lymphoma treated by standard CHOP regimen. Chin J Cancer 23 (Suppl 11): S1443-S1447, 2004 (In Chinese).

21. Haas PS, Denz U, Ihorst G and Engelhardt M: Thalidomide in consecutive multiple myeloma patients: single-center analysis on practical aspects, efficacy, side effects and prognostic factors with lower thalidomide doses. Eur J Haematol 80: 303-309, 2008.

22. Eisenhauer EA, Therasse P, Bogaerts J, et al: New response evaluation criteria in solid tumours: revised RECIST guideline (version 1.1). Eur J Cancer 45: 228-247, 2009.

23. NCI: Cancer therapy evaluation program, common terminology criteria for adverse events. Version 3.0, Dec 12, 2003. Available at http://ctep.cancer.gov/protocolDevelopment/electronic_applications/docs/ctcaev3.pdf. Accessed May 18, 2014.

24. Rapisarda A and Melillo G: Role of the VEGF/VEGFR axis in cancer biology and therapy. Adv Cancer Res 114: 237-267, 2012

25. Govindarajan R: Irinotecan/thalidomide in metastatic colorectal cancer. Oncology (Williston Park) 16 (Suppl 3): S23-S26, 2002.

26. Majumder S, Sreedhara SR, Banerjee S and Chatterjee S: TNF a signaling beholds thalidomide saga: a review of mechanistic role of TNF- $\alpha$ signaling under thalidomide. Curr Top Med Chem 12: $1456-1467,2012$

27. Ladizinski B, Shannon EJ, Sanchez MR and Levis WR: Thalidomide and analogues: potential for immunomodulation of inflammatory and neoplastic dermatologic disorders. J Drugs Dermatol 9: 814-826, 2010

28. Mei SC and Wu RT: The G-rich promoter and G-rich coding sequence of basic fibroblast growth factor are the targets of thalidomide in glioma. Mol Cancer Ther 7: 2405-2414, 2008.

29. Rafiee P, Stein DJ, Nelson VM, Otterson MF, Shaker R and Binion DG: Thalidomide inhibits inflammatory and angiogenic activation of human intestinal microvascular endothelial cells (HIMEC). Am J Physiol Gastrointest Liver Physiol 298 : G167-G176, 2010.
30. Lin YC, Shun CT, Wu MS and Chen CC: A novel anticancer effect of thalidomide: inhibition of intercellular adhesion molecule-1-mediated cell invasion and metastasis through suppression of nuclear factor-kappaB. Clin Cancer Res 12: 7165-7173, 2006

31. Zhu YX, Kortuem KM and Stewart AK: Molecular mechanism of action of immune-modulatory drugs thalidomide, lenalidomide and pomalidomide in multiple myeloma. Leuk Lymphoma 54: 683-687, 2013

32. Strupp C, Aivado M, Germing U, Gattermann N and Haas R: Angioimmunoblastic lymphadenopathy (AILD) may respond to thalidomide treatment: two case reports. Leuk Lymphoma 43: 133-137, 2002.

33. Wilson EA, Jobanputra S, Jackson R, Parker AN and McQuaker IG: Response to thalidomide in chemotherapy-resistant mantle cell lymphoma: a case report. Br J Haematol 119: 128-130, 2002.

34. Damaj G, Lefrère F, Delarue R, Varet B, Furman R and Hermine O: Thalidomide therapy induces response in relapsed mantle cell lymphoma. Leukemia 17: 1914-1915, 2003.

35. Pro B, Younes A, Albitar M, et al: Thalidomide for patients with recurrent lymphoma. Cancer 100: 1186-1189, 2004.

36. Su X, Zhang R, Liu H, et al: Clinical study of E-CHOP plus thalidomide in treatment of advanced non-Hodgkin's lymphoma. China Pharmaceuticals 17: 53-55, 2008.

37. Damaj G, Bouabdallah R, Vey N, Bilger K, Mohty M and Gastaut JA: Single-agent thalidomide induces response in T-cell lymphoma. Eur J Haematol 74: 169-171, 2005.

38. Dogan A, Ngu LS, Ng SH and Cervi PL: Pathology and clinical features of angioimmunoblastic T-cell lymphoma after successful treatment with thalidomide. Leukemia 19: 873-875, 2005.

39. Tassinari D, Santelmo C, Tombesi P and Sartori S: Thalidomide in the treatment of cancer cachexia. J Palliat Care 24: 187-189, 2008.

40. Carrier M, Le Gal G, Tay J, Wu C and Lee AY: Rates of venous thromboembolism in multiple myeloma patients undergoing immunomodulatory therapy with thalidomide or lenalidomide: a systematic review and meta-analysis. J Thromb Haemost 9: 653-663, 2011.

41. Zhu D, Co rral LG, Fleming YW and Stein B: Immunomodulatory drugs Revlimid (lenalidomide) and CC-4047 induce apoptosis of both hematological and solid tumor cells through NK cell activation. Cancer Immunol Immunother 57: 1849-1859, 2008. 